\title{
Experiences of COVID-19 in Africa
}

\author{
Timely information for understanding the socioeconomic impact of COVID-19 in low-income countries is very \\ limited. A recent paper by Josephson, Kilic, and Michler reveals large and disproportionate socioeconomic impacts \\ of the pandemic and provides useful insights to inform an appropriate policy response.
}

\section{Patrick Opoku Asuming}

$\mathrm{C}$ OVID-19 is a global pandemic with potentially damaging socioeconomic impacts. An appropriate policy response requires timely information on the scale of the impact as well as how it affects different segments of the population. Yet, information for understanding the socioeconomic impact of COVID-19 is very limited, especially in low-income countries. A recent paper by Josephson, Kilic, and Michler in Nature Human Behaviour provides timely important insights on the socioeconomic impact of COVID-19 to inform policy response by governments and development partners.

The COVID-19 pandemic is primarily a health shock with severe economic and social impacts. The pandemic, as well as the measures adopted to halt the spread of the infections, has brought economic activity to a halt in most places. The lockdowns, quarantines, travel bans, business closures, and school closedowns have been projected to shrink the world economy by more than $8 \%$, pushing more than 88 million people into extreme poverty ${ }^{1}$. The scale of the socioeconomic impact is expected to differ across countries. More importantly, even within an individual country it is expected that impact of COVID-19 will differ based on income, education, and geographic residence $^{2,3}$. Differential impact of COVID19 is likely to be more pronounced in low-income countries because of rising inequalities in many of these countries prior to the pandemic ${ }^{4}$. In the case of African economies dominated by informal business owners who literally live 'hand-to-mouth' or day-by-day, the potential for COVID-19 to increase inequality is elevated. This is because the formal-informal divide has greatly affected the ability to maintain jobs and means of livelihoods during lockdowns.

An appropriate policy response to address the socioeconomic effects of COVID-19, therefore, requires accurate information on the socioeconomic impact as the pandemic evolves. Such information will answer important questions, including: what is the magnitude of the socioeconomic impact of COVID-19? Which groups of individuals have been most affected? What strategies have different groups adopted to cope with the pandemic? Unfortunately, accurate recent information on these, particularly in African countries, is simply lacking.

It is for this reason that the recent paper by Josephson, Kilic, and Michler is as insightful as is it timely ${ }^{5}$. In this paper, the authors present information on the socioeconomic impact of COVID-19 from ongoing periodic phone surveys on the living conditions and livelihoods of people in four African countries: Ethiopia, Malawi, Nigeria, and Uganda. There are several strong points in the data used by the authors. First, the samples for each country are built on nationally representative household samples from the respective countries. Second, the information was collected using comparable questions from the various countries, so the findings are comparable. Third, for most indicators presented, authors have access to similar indicators for the period before COVID-19, so it is easier to compare the information collected in the COVID era with similar information collected in the pre-COVID-19 period.

The paper revealed that $42 \%$ of households in these countries have suffered a job loss, business closure, disruption of farming activity, rising input prices, falling output prices, increasing food prices, or illness and/or death of an income earner since the onset of the pandemic. Following this, the paper finds that $77 \%$ of the population in these countries have lost income during the pandemic. This translates to 256 million individuals being affected by the loss of income. Interestingly, just about the same number of individuals (257 million) expressed concerns about financial threats due to COVID-19. There is considerable disparity in the fraction of households that have lost incomes across the four countries. This is important because it shows that a one-size-fits-all policy would not work for countries even from the same continent. The authors also found evidence of a potential rise in food insecurity during the pandemic. In particular, in Nigeria, where the authors have information before and after the onset of the pandemic, they find a significant increase in food insecurity. Individuals experiencing food insecurity are also very concerned about their health and financial security.

This is further compounded by findings that people have struggled to access basic supplies, especially medicines and staple food during the pandemic, as the paper finds that $29 \%$ and $30 \%$ of individuals who wanted to buy medicines and staple food respectively, were unable to buy these items. To cope with these challenges, affected households have resorted to living off savings, selling assets, and reducing food consumption, among other strategies. The coping strategies differed between rural and urban residents, which suggests that governments' responses should be more nuanced to better help households recover from the effects of the pandemic.

The paper also finds that the burdens of the pandemic and the policy interventions to curtail the spread of the disease have fallen disproportionately on the poorest. For instance, in terms of the effect on education, the paper finds that children from the poorest $60 \%$ of the population were less likely to have engaged in any learning activity, compared with their counterparts in the richest $40 \%$ of the population.

Overall, as the authors point out in their discussion, their findings bring to the fore the need to strengthen social protection systems in low-income countries. This should be situated in the broader context of policies to reduce the rising inequality in many such countries.

Despite the importance of the findings contained in the paper, there are some limitations. To begin with, the results are limited to only four African countries. This is hardly representative of low-income countries. The disparities in the findings across the four nations indicate that the 
impact of COVID-19 is context-specific, and thus it is imperative for various governments to collect the relevant information to address the specific challenges posed by COVID-19 in their respective countries. In addition, the findings presented in the paper reflect data collected up to August 2020. As the pandemic is still evolving, the findings are likely to represent only the short-run effects of the pandemic. It will be important to understand the fuller socioeconomic effects of the pandemic over an extended period. Thankfully, the authors indicate that data collection efforts are ongoing and are being expanded to include many more countries. Findings from the expanded set of countries and over a longer duration cannot come early enough.

Patrick Opoku Asuming (D)

Department of Finance, University of Ghana Business School, Accra, Ghana.

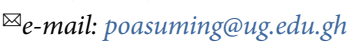

Published online: 7 April 2021

https://doi.org/10.1038/s41562-021-01105-9
References

1. Global Economic Prospects https://www.worldbank.org/en/ publication/global-economic-prospects (World Bank, 2020).

2. Berkhout, E. et al. The Inequality Virus https://www.oxfam.org/ en/research/inequality-virus (Oxfam International, 2021).

3. Ahmed, F., Ahmed, N., Pissarides, C. \& Stiglitz, J. Lancet Pub. Health. 5, e240 (2020).

4. United Nations Department of Economic and Social Affairs. World Social Report 2020: Inequality in a Rapidly Changing World https://www.un.org/development/desa/dspd/world-socialreport/2020-2.html (United Nations Publications, 2020).

5. Josephson, A., Kilic, T. \& Michler, J. D. Nat. Hum. Behav. https:// doi.org/10.1038/s41562-021-01096-7 (2021).

Competing interests

The author declares no competing interests. 